\title{
Colonoscopy-related injury among colonoscopists: an international survey
}

\section{(ㄷ)(1) $\odot$}

\author{
Authors \\ Ammar Al-Rifaie ${ }^{1}$, Mohammed Gariballa ${ }^{1}$, Alhassan Ghodeif ${ }^{1}$, Stephen Hodge ${ }^{2}$, Mo Thoufeeq ${ }^{1}$, Mark Donnelly $^{1}$
}

Institutions

1 Sheffield Teaching Hospitals, Sheffield, UK

2 Calderdale \& Huddersfield Hospitals, Huddersfield, UK

submitted 9.6.2020

accepted after revision $\quad 7.10 .2020$

Bibliography

Endoscopy International Open 2021; 09: E102-E109

DOI 10.1055/a-1311-0561

ISSN 2364-3722

(C) 2021. The Author(s).

This is an open access article published by Thieme under the terms of the Creative Commons Attribution-NonDerivative-NonCommercial License, permitting copying and reproduction so long as the original work is given appropriate credit. Contents may not be used for commecial purposes, or adapted, remixed, transformed or built upon. (https://creativecommons.org/licenses/by-nc-nd/4.0/)

Georg Thieme Verlag KG, Rüdigerstraße 14,

70469 Stuttgart, Germany

Corresponding author

Ammar Al-Rifaie, Sheffield Teaching Hospitals NHS

Foundation Trust - Gastroenterology, Herries Road Sheffield

S10 2JF, United Kingdom of Great Britain and Northern Ireland ammar.al-rifaie@nhs.net

Supplementary material is available under https://doi.org/10.1055/a-1311-0561

\section{ABSTRACT}

Background and study aims Colonoscopy is physically demanding for endoscopists and patients. Repetitive movements during colonoscopy can lead to overuse injuries. We aimed to explore the prevalence and range of colonoscopyrelated musculoskeletal injuries (CRIs) in endoscopists.

Methods A cross-sectional electronic survey of 1825 endoscopists was performed. The sample was composed of members of the British Society of Gastroenterology, European Society of Gastrointestinal Endoscopy, and National Nurse Endoscopy Group (UK). The survey comprised 20 questions. These included: endoscopists' workload, level of experience, and their perceived CRIs. All endoscopists who perform colonoscopy independently were included in the analysis.

Results A total of 368 questionnaires were completed of 1825 surveyed (20.16\%). Of those, 319 participants $(17.48 \%)$ were fully independent in colonoscopy. Of 319 endoscopists, 254 (79.6\%) have experienced musculoskeletal injuries. These were reported as either possibly ( $n=143,56.3 \%)$ or definitely $(n=90,35.4 \%)$ related to colonoscopy. Commonly injured areas were the lower back $(n=85,36.5 \%)$, neck $(n=82,35.2 \%)$ and left thumb $(n=$ 79, 33.9\%). Of the injured endoscopists, 98 (30.7\%) made some modification to their practice, such as stretching exercises and ergonomic changes. Of the endoscopists, 134 (42.0\%) thought that repetitive limb strain was a likely causative mechanism. Around $40 \%$ believed that torquing the scope and challenging body position were precipitating CRIs. Several treatment modalities were used to treat CRIs. These included; physiotherapy $(n=109)$, medications $(n=$ $70)$, rest $(n=43)$, splinting $(n=31)$, steroid injections $(n=$ 26) and surgery $(n=11)$.

Conclusions A significant proportion of colonoscopists experience CRIs. The majority of the suggested modifications to practice can be adopted by any endoscopist. These results highlight the need to recognise CRI as an important occupational health hazard and to adopt preventative strategies routinely in the future.

\section{Introduction}

Endoscopy has become a widespread and invaluable tool in modern gastroenterology. In particular, colonoscopy is the gold standard modality for investigating colorectal symptoms and is currently endorsed as a primary screening tool for colo- rectal cancer in many healthcare systems. Technological advances in endoscopy have led to a huge improvement in the ability of gastroenterologists to diagnose and treat a wide range of simple to complex presentations. However, this may have exposed endoscopists to various occupational hazards, especially musculoskeletal (MSK) injuries [1-4]. 
Endoscopists are commonly prone to endoscopy-related musculoskeletal injury and pain, which can occur in different parts of the body secondary to the complex and repetitive techniques associated with endoscopy procedures. However, many of these studies may be biased due to the limitation of self-reporting injuries $[5,6]$.

A systematic review of 13 studies revealed that $39 \%$ to $89 \%$ of endoscopists suffered from pain or injury in relation to endoscopy. That mainly affected the back, neck, shoulders, elbows, hands, and fingers. Endoscopists often use an extreme range of joint movement, which increases the risk of injury [7, 8].

In the United States, nearly half of gastroenterology fellows were affected by MSK injuries [9] with female fellows being more vulnerable to such injuries [10]. Other risk factors reported were the duration and number of the procedures and age of the endoscopist [7-10].

While many endoscopists suffer from such injuries, little is being done to prevent them. Training in ergonomics seemed to be relatively protective; however, not many gastroenterologists have had such training [9-11].

Our study aimed to explore the prevalence and range of colonoscopy-related MSK injuries (CRIs) in endoscopists. We also examined the factors that may predispose endoscopists to acquire MSK injury, and the possible consequences of CRI including sick leave, treatment, and modifications to practice.

\section{Methods}

\section{Survey development and sampling}

Our cross-sectional, electronic survey comprising 20 questions was modeled after the 2015 ASGE (American Society for Gastrointestinal Endoscopy) survey [6]. Our survey was pilot tested with a small number of experienced endoscopists at our center before distribution (Appendix 1).

In February 2018, an online survey tool was used to collect responses. The link to the survey was sent via email to 1825 endoscopists. They were all members of the British Society of Gastroenterology, the European Society of Gastrointestinal Endoscopy or the National Nurse Endoscopy Group (UK). Email databases were obtained from each of the societies and the survey was sent to each individual in them.

The stated aim of the survey was to explore the prevalence of colonoscopy-related MSK injuries and their impact on colonoscopists. We also explained that the survey would take 5 minutes to complete and that all responses would remain anonymous. The endoscopists were encouraged to forward the survey to their colleagues. All endoscopists who perform colonoscopy independently were included in the analysis. The data were collected between January 27, 2018 and February 2, 2018. By completing the online survey, informed consent was presumed by respondents.

\section{Survey questions}

The 20 questions explored the job role of the endoscopist, demographics such as age and gender, the country where they worked, endoscopists' workload, level of experience, their per- ceived CRI and any consequences from CRI that they encounter. The full questionnaire is summarized in Appendix $\mathbf{1}$.

\section{Statistical analysis}

Descriptive statistics were used to identify the frequencies of CRI among colonoscopists. The respondents were divided into two groups: colonoscopists who believe or suspect that colonoscopy has precipitated their injury and colonoscopists who do not have any injury or believe that their injury is not caused by colonoscopy.

Comparative statistics using a chi-square test were applied to define the statistical difference between groups in relation to different dependent variables. To identify risk factors by using a chi-square test, different cut-offs were examined for the continuous numeric variables, for example, the number of colonoscopies per year, total lifetime procedures, the number of hours per week, and the number of years performing colonoscopy.

We also performed binominal logistic regression to identify factors associated with CRI. Variables with a $P<0.15$ were incorporated into a multivariate logistic regression model to confirm their independent association with CRI. $P<0.05$ was considered to represent a statistically significant difference between groups. IBM SPSS V.22.0 statistics were used for the analysis.

\section{Results}

A total of 368 colonoscopists completed the questionnaire from a total sample size of 1825 (20.16\%). Of those, 319 participants $(17.48 \%)$ were fully independent in colonoscopy and are included in this study. The majority of respondents were gastroenterologists $(216 / 67.7 \%)$, followed by nurse endoscopists (80/25.1\%) and surgeons (23/7.2\%). The ratio of male to female colonoscopists was $2.1: 1$. The majority of responding colonoscopists were aged 31 to 60 years (89.5\%); $1.0 \%$ were less than 30 years old and $9.5 \%$ were over age 60 ( $\triangleright$ Table 1 ).

The included responses were from 45 countries around the world. The responding colonoscopists were mainly from the UK (231/72.4\%). Forty-eight respondents (15.0\%) were from the rest of Europe, 15 (4.7\%) were from Asia and Australia, 14 responders (4.4\%) were from North and South America and another 11 (3.4\%) were from Africa.

The participating colonoscopists were nearly equally split in terms of their hospital or health care practice. Of the colonoscopists, 170 (53.3\%) work in a teaching hospital or an academic center, compared to $149(46.7 \%)$ in a district hospital or community practice. The most commonly used endoscopy system was Olympus (270/84.6\%) followed by Fujifilm (25/7.8\%) and Pentax (24/7.5\%).

Of the 319 respondents, 254 (79.6\%) have experienced MSK injuries. These were reported as either possibly (143/56.3\%) or definitely (90/35.4\%) related to colonoscopy ( $>$ Fig. $\mathbf{1})$.

On initial chi-squared analysis, female endoscopists were found to have a significantly higher rate of CRI $(P=0.004)$ and to be more likely to require time off work $(P=0.0001)$. Other factors like hours per week spent performing a colonoscopy, total life-time procedures, the number of procedures per year, 
- Table 1 Baseline characteristics, $\mathrm{n}=319$

\begin{tabular}{|c|c|c|c|c|}
\hline Factor & No. (\%) & $\begin{array}{l}\text { Possible/definite } \\
\text { CRI, n = } 236(\%)\end{array}$ & $\begin{array}{l}\text { No CRI, } \\
n=83(\%)\end{array}$ & $P$ \\
\hline \multicolumn{5}{|l|}{ Job Role } \\
\hline - Gastroenterologist & $216(67.7)$ & $158(73.1)$ & $58(26.9)$ & \multirow[t]{3}{*}{0.162} \\
\hline - Surgeon & $23(7.2)$ & $14(60.9)$ & $9(39.1)$ & \\
\hline - Nurse endoscopist & $80(25.1)$ & $64(80)$ & $16(20)$ & \\
\hline \multicolumn{5}{|l|}{ Age } \\
\hline - 20-30 & $3(0.9)$ & $1(33.3)$ & $2(66.7)$ & \multirow[t]{5}{*}{0.444} \\
\hline - 31-40 & $63(19.7)$ & $49(77.8)$ & $14(22.2)$ & \\
\hline . $41-50$ & $135(42.3)$ & $102(75.6)$ & $33(24.4)$ & \\
\hline - 51-60 & $88(27.6)$ & $63(71.6)$ & $25(28.4)$ & \\
\hline . $>60$ & $30(9.4)$ & $21(70.0)$ & $9(30.0)$ & \\
\hline \multicolumn{5}{|l|}{ Gender } \\
\hline - Male & $217(68.0)$ & $150(69.1)$ & $67(30.9)$ & \multirow[t]{2}{*}{0.004} \\
\hline - Female & $102(32.0)$ & $86(84.3)$ & $16(15.7)$ & \\
\hline \multicolumn{5}{|l|}{ Country/continent } \\
\hline - UK & $231(72.4)$ & $170(73.6)$ & $61(26.4)$ & \multirow[t]{5}{*}{0.989} \\
\hline - Europe & $48(15.0)$ & $37(77.1)$ & $11(22.9)$ & \\
\hline - Asia and Australia & $15(4.7)$ & $11(73.3)$ & $4(26.7)$ & \\
\hline - North and South America & $14(4.4)$ & $10(71.4)$ & $4(28.6)$ & \\
\hline - Africa & $11(3.4)$ & $8(72.7)$ & $3(27.3)$ & \\
\hline \multicolumn{5}{|l|}{ Hospital or health practice } \\
\hline $\begin{array}{l}\text { - District hospital/community practice with }<5 \text { specialists perform- } \\
\text { ing endoscopy }\end{array}$ & $22(6.9)$ & $21(95.5)$ & $1(4.5)$ & \multirow[t]{4}{*}{0.073} \\
\hline $\begin{array}{l}\text { " District hospital/community practice with } \geq 5 \text { specialists perform- } \\
\text { ing endoscopy }\end{array}$ & $127(39.8)$ & $88(69.3)$ & $39(30.7)$ & \\
\hline $\begin{array}{l}\text { - Teaching hospital/academic practice (university-affiliated group } \\
\text { with }<5 \text { specialists performing endoscopy) }\end{array}$ & $28(8.8)$ & $20(71.4)$ & $8(28.6)$ & \\
\hline $\begin{array}{l}\text { - Teaching hospital/academic practice (university-affiliated group } \\
\text { with } \geq 5 \text { specialists performing endoscopy) }\end{array}$ & $142(44.5)$ & $107(75.4)$ & $35(24.6)$ & \\
\hline \multicolumn{5}{|l|}{ Video Endoscopy System } \\
\hline - Olympus & $270(84.6)$ & $197(73.0)$ & $73(27.0)$ & \multirow[t]{3}{*}{0.622} \\
\hline " Fujifilm & $25(7.8)$ & $20(80.0)$ & $5(20.0)$ & \\
\hline - Pentax & $24(7.5)$ & $19(79.2)$ & $5(20.8)$ & \\
\hline \multicolumn{5}{|l|}{ Colonoscopies/year } \\
\hline - $<150$ & $55(17.2)$ & $38(69.1)$ & $17(30.9)$ & \multirow[t]{2}{*}{0.399} \\
\hline . $>150$ & $264(82.8)$ & $198(75.0)$ & $66(25.0)$ & \\
\hline \multicolumn{5}{|l|}{ Lifetime total } \\
\hline . $<5000$ & $199(62.4)$ & $147(73.9)$ & $52(26.1)$ & \multirow[t]{2}{*}{0.973} \\
\hline . $>5000$ & $120(37.6)$ & $89(74.2)$ & $31(25.8)$ & \\
\hline \multicolumn{5}{|l|}{ Hour/week } \\
\hline - $<6$ & $46(14.4)$ & $35(76.1)$ & $11(23.9)$ & \multirow[t]{2}{*}{0.856} \\
\hline . $>6$ & $273(85.6)$ & $201(73.6)$ & $72(26.4)$ & \\
\hline
\end{tabular}


$>$ Table 1 (Continuation)

\begin{tabular}{|c|c|c|c|c|}
\hline Factor & No. $(\%)$ & $\begin{array}{l}\text { Possible/definite } \\
\text { CRI, n = } 236(\%)\end{array}$ & $\begin{array}{l}\text { No CRI, } \\
n=83(\%)\end{array}$ & $P$ \\
\hline \multicolumn{5}{|c|}{ Years performing colon } \\
\hline . $0-5$ & $58(18.2)$ & $43(74.1)$ & $15(25.9)$ & \multirow[t]{3}{*}{0.945} \\
\hline - $6-10$ & $63(19.7)$ & $46(73.0)$ & $17(27.0)$ & \\
\hline . $>10$ & $198(62.1)$ & $147(74.2)$ & $51(25.8)$ & \\
\hline
\end{tabular}

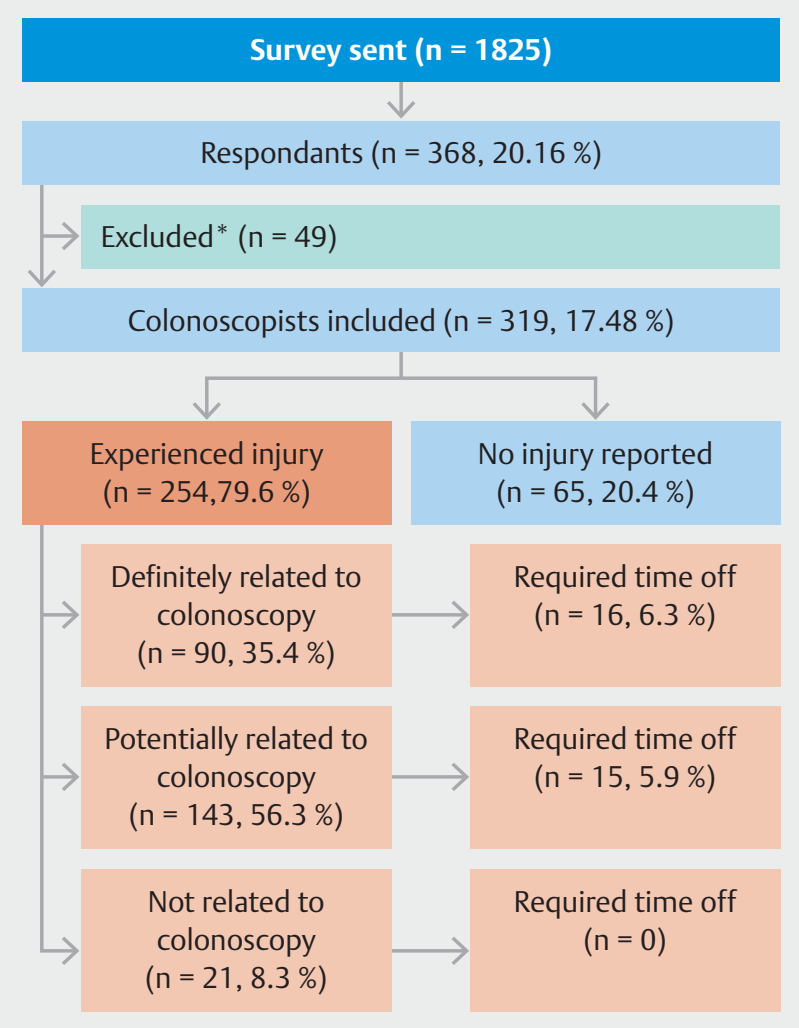

Fig. 1 Study cohort. * Excluded as not fully independent in colonoscopy.

type of health care practice, endoscopy system in use, and number of years performing colonoscopy were not found to be significantly associated with higher rates of CRI ( $\bullet$ Table 1 ). The prevalence of MSK that is definitely or possibly related to CRI was highest among nurse endoscopists (64/80\%), followed by gastroenterologists (158/73.1\%) and surgeons (14/60.9\%).

On univariate binominal logistic regression ( $\bullet$ Table 2$)$, female gender (odds ratio [OR] 2.392; $95 \%$ confidence interval [Cl] [1.260-4.542]; $P=0.008$ ) and surgeon operators (OR 3.375; $95 \% \mathrm{Cl}$ [1.192-9.552]; $P=0.022$ ) were associated with more CRI. Combining the above factors with the hospital factor as district hospital/community practice with less than five specialists performing endoscopy had a $P<0.15(P=0.077)$ in a multivariable regression model. Gender (covariate adjusted [OR] 2.198; $95 \% \mathrm{Cl}[0.925-5.223] ; P=0.075)$ and surgeon operator (covariate adjusted [OR]1.856; $95 \% \mathrm{Cl}$ [0.523-6.591] $P=0.339$ ) were no longer statistically significant.

Commonly injured areas were the lower back (85/36.5\%), neck $(82 / 35.2 \%)$ and left thumb $(79 / 33.9 \%)$. A full description of other injuries is presented in $>$ Table 3 . The majority of injured endoscopists (98/30.7\%) made some modification to their practice due to CRI, such as performing stretching exercises or adjusting ergonomics. However, 163 (51.1\%) reported at least one modification to practice irrespective of the cause ( Fig.2). Other modifications reported were regular massages, upper limb splints, straps and supporting devices, alternating gastroscopies and colonoscopies during the same list, technique modifications, help from an assistant endoscopist, and not performing endoscopy all day.

Of the endoscopists, $134(42 \%)$ thought that repetitive strain was the likely causative mechanism. Around $40 \%$ believed that torquing the scope and challenging body position were the precipitating factors of CRI ( $\triangleright$ Fig. 3 ).

Several treatment modalities were used: physiotherapy (109), medications (70), rest (43), splinting (31), steroid injections (26), and surgery (11).

CRI caused some respondents to take sick leave (31/9.7\%); in total, 212 weeks were taken. Sick leaves ranged between 1 day and 3 months (median 2 weeks). Six colonoscopists reported more than one episode of sickness absence likely due to performing colonoscopy. Two colonoscopists stopped doing colonoscopies and one reduced his working hours to part-time.

\section{Discussion}

This is the largest international survey to examine the issue of CRI, that is, injury to the colonoscopist rather than to the patient. It demonstrates that CRIs are prevalent among endoscopists with nearly three-quarters of respondents $(73 \%)$ reporting a MSK injury possibly or definitely related to performing colonoscopy. This reported rate of injury falls at the higher range of previous estimated rates of $39 \%$ to $89 \%$, underscoring the fact that it remains an occupational health issue in today's practice [7]. The impact of CRI extends beyond the individual endoscopists and can also affect service provision. In extreme cases, endoscopists may be forced to reduce endoscopy commitments or rarely, have to cease performing colonoscopy en- 
- Table 2 Factors predictive of CRI.

\begin{tabular}{|c|c|c|c|c|}
\hline Factor & $\begin{array}{l}\text { Unadjusted OR } \\
(95 \% \mathrm{Cl})\end{array}$ & $P$ value & $\begin{array}{l}\text { Covariate adjusted } \\
\text { OR }(95 \% \mathrm{Cl})\end{array}$ & $P$ value \\
\hline \multicolumn{5}{|l|}{ Job Role } \\
\hline - Gastroenterologist & $1.1761(0.881-3.521)$ & 0.109 & $1.064(0.422-2.6810)$ & 0.896 \\
\hline - Surgeon & $3.375(1.192-9.552)$ & 0.022 & $1.856(0.523-6.591)$ & 0.339 \\
\hline - Nurse endoscopist & \multicolumn{4}{|l|}{ Reference } \\
\hline Age & $1.140(0.854-1.521)$ & 0.375 & & \\
\hline \multicolumn{5}{|l|}{ Gender } \\
\hline - Male & \multicolumn{4}{|l|}{ Reference } \\
\hline - Female & $2.392(1.260-4.542)$ & 0.008 & $2.198(0.925-5.223)$ & 0.075 \\
\hline \multicolumn{5}{|l|}{ Country/Continent } \\
\hline - UK & $0.810(0.207-3.165)$ & 0.761 & & \\
\hline - Europe & $0.793(0.179-3.510)$ & 0.760 & & \\
\hline - Asia and Australia & $0.970(0.168-5.593)$ & 0.973 & & \\
\hline - North and South America & $1.185(0.201-6.987)$ & 0.851 & & \\
\hline - Africa & \multicolumn{4}{|l|}{ Reference } \\
\hline \multicolumn{5}{|l|}{ Hospital or health practice } \\
\hline $\begin{array}{l}\text { - District hospital/community practice with }<5 \text { specialists per- } \\
\text { forming endoscopy }\end{array}$ & $0.158(0.020-1.219)$ & 0.077 & $0.141(0.018-1.101)$ & 0.062 \\
\hline $\begin{array}{l}\text { - District hospital / community practice with } \geq 5 \text { specialists per- } \\
\text { forming endoscopy }\end{array}$ & $1.271(0.724-2.233)$ & 0.404 & & \\
\hline $\begin{array}{l}\text { - Teaching hospital /academic practice (University-affiliated } \\
\text { group with<5 specialists performing endoscopy) }\end{array}$ & $1.159(0.450-2.989)$ & 0.760 & & \\
\hline $\begin{array}{l}\text { - Teaching hospital/academic practice (University-affiliated } \\
\text { group with } \geq 5 \text { specialists performing endoscopy) }\end{array}$ & \multicolumn{4}{|l|}{ Reference } \\
\hline \multicolumn{5}{|l|}{ Video Endoscopy System } \\
\hline - Olympus & $1.333(0.481-3.695)$ & 0.580 & & \\
\hline - Pentax & $0.667(0.139-3.194)$ & 0.612 & & \\
\hline - Fujifilm & \multicolumn{4}{|l|}{ Reference } \\
\hline Colonoscopy/year & $0.707(0.362-1.380)$ & 0.309 & & \\
\hline Life-time total & $0.936(0.540-1.621)$ & 0.812 & & \\
\hline Hour/week & $0.968(0.463-2.023)$ & 0.931 & & \\
\hline Years performing colon & $0.965(0.692-1.348)$ & 0.836 & & \\
\hline
\end{tabular}

tirely. Although only a few endoscopists had to stop doing colonoscopies or reducing numbers performed due to CRI, more than 4 years of activity were lost due to sickness by 31 respondents.

A recent European nationwide survey reported endoscopyrelated MSK injuries at a prevalence of $69.6 \%$, which is similar to the prevalence in our survey [12]. Procedural volume and cumulative procedural time spent have previously been recognized as risk factors for CRI $[7,13,14]$. These risk factors were not observed in our study. A significant statistical difference might be captured with an even higher number of participants. On the other hand, the actual scoping technique and ergonomics used by individual colonoscopist may also be important risk factors for MSK injury. Further studies to explore this are needed.

On univariate analysis, we observed a higher rate of CRI among females in our survey. However, after controlling for other variables in the multivariable regression, it was not iden- 
- Table 3 MSK injury definitely or potentially related to colonoscopy $(\mathrm{n}=233)^{1}$.

\begin{tabular}{|l|l|}
\hline Injury & No. (\%) \\
\hline Right fingers & $38(16.3 \%)$ \\
\hline Right thumb & $41(17.6 \%)$ \\
\hline Right hand & $44(18.9 \%)$ \\
\hline Right wrist & $57(24.5 \%)$ \\
\hline Right elbow & $30(12.9 \%)$ \\
\hline Right shoulder & $63(27.0 \%)$ \\
\hline Left fingers & $34(14.6 \%)$ \\
\hline Left thumb & $79(33.9 \%)$ \\
\hline Left hand & $25(10.7 \%)$ \\
\hline Left wrist & $27(11.6 \%)$ \\
\hline Left elbow & $26(11.2 \%)$ \\
\hline Left shoulder & $37(15.9 \%)$ \\
\hline Carpal tunnel & $13(5.6 \%)$ \\
\hline Neck & $82(35.2 \%)$ \\
\hline Upper back & $47(20.2 \%)$ \\
\hline Lower back & $85(36.5 \%)$ \\
\hline Hip & $13(5.6 \%)$ \\
\hline Right lower limb & $8(3.4 \%)$ \\
\hline Left lower limb & $5(2.1 \%)$ \\
\hline Other injuries & $21(9.0 \%)$ \\
\hline MSK, musculoskeletal; CRI, colonoscopy-related injury. \\
\hline Multiple injuries reported by some colonoscopists. The mean number of \\
\hline CRIs/colonoscopist is 3.3). & \\
\hline
\end{tabular}

tified as an independent predictor for CRI. A recent European nationwide survey on endoscopy-related MSK injuries and a survey of US gastroenterology fellows have reported female gender as a risk factor for endoscopy-related injuries [10, 12]. The combination of a suboptimal grip and reduced force-generating muscle mass has been described as placing females at a higher risk of repetitive strain injury [15]. One study of gastroenterology fellows reported that hand size could affect the ability to learn and perform endoscopy, with smaller hand size being more prevalent in women [16]. This may indicate that female endoscopists are at increased risk for this occupational hazard and highlights the need for further potentially genderbased surveys/studies to identify other gender-specific risk factors. This may lead to adjustments in colonoscopy education and in ergonomics of colonoscope design to accommodate a wider range of physical attributes.

The commonly injured areas reported in our survey were the lower back, neck, and left thumb. The repetitive hand motion and action of torquing the scope were the most common mechanisms leading to left thumb injuries. The phenomenon of colonoscope's thumb, i.e. De Quervain's tenosynovitis of the left thumb due to repeated forces required to manipulate the colonoscope against resistance, has been described [17]. Technique modification has been implemented by many of our respondents. Stretching exercises, using height-adjustable beds and monitors, and improving handgrip by using towels to hold the scope are among the most popular modifications to mitigate the effects of this strain over a career span. Other interesting modifications reported were regular massages, upper limb splints, straps and supporting devices, alternating gastroscopies and colonoscopies during the same list, technique modifications, and not performing endoscopy all day. The utilization of an assistant endoscopist to cover lists as a short-term solution was available to a minority of respondents. This is unlikely to be accessible in all centers. This, however, might be available in large centers that offer complex therapeutic colonoscopy.

The back and neck pain injuries were mostly attributed to awkward posture, lengthy standing, and incorrect bed height. Spatial limitations of procedure rooms for optimal scope/bedscreen alignment to help maintain natural posture were frequently blamed. Ergonomic specifications to optimize bed height and monitor distance and elevation have been suggested but their rate of implementation into routine practice is unknown [18-20]. More studies assessing the effect of the implementation of ergonomic specifications into standard practice are required. Appraisal of endoscopy technique by trained occupational therapists has been reported to have some benefit [15]. A recent study assessing the impact of simulation-based ergonomic training curriculum that includes lectures, watching videos of expert performance, and ergonomic-specific feedback was found to be associated with a lower rate of CRI [21].

A wide variety of treatment modalities were used by colonoscopists with CRI; they ranged from simple, noninvasive interventions like physiotherapy, analgesia, rest and splinting, to more invasive and sometimes complex interventions like steroid intra-articular injections and surgery. This is indicative of the individual impact CRI is having on our endoscopists. There is a call among our respondents for health care providers to cap the number of service procedures for colonoscopists to reduce long-term CRI. This will be challenging, given the increasing demands on colonoscopy; however, a suitable limit that satisfies service provision and training requirements will need careful consideration. These policies, in combination with targeted education on ergonomic procedure technique and workstation design with advances in scope technology, could be the strategy moving forward.

Looking to the future, CRI may become more prevalent as the number of colonoscopy procedures being performed is rising. For example, the introduction of FIT (fecal immunochemical testing) in the National Health Service bowel cancer screening program has led to a significant increase in the number of screening invitations [22]. Gerghaty et al. identified bowel cancer screeners as a higher-risk group due to higher-intensity workload and this risk magnitude is likely to increase over the coming years [13]. Our findings can be useful for endoscopists and hospitals, as there may be an increased demand for endoscopy in the COVID-19 recovery phase to deal with the backlog. 


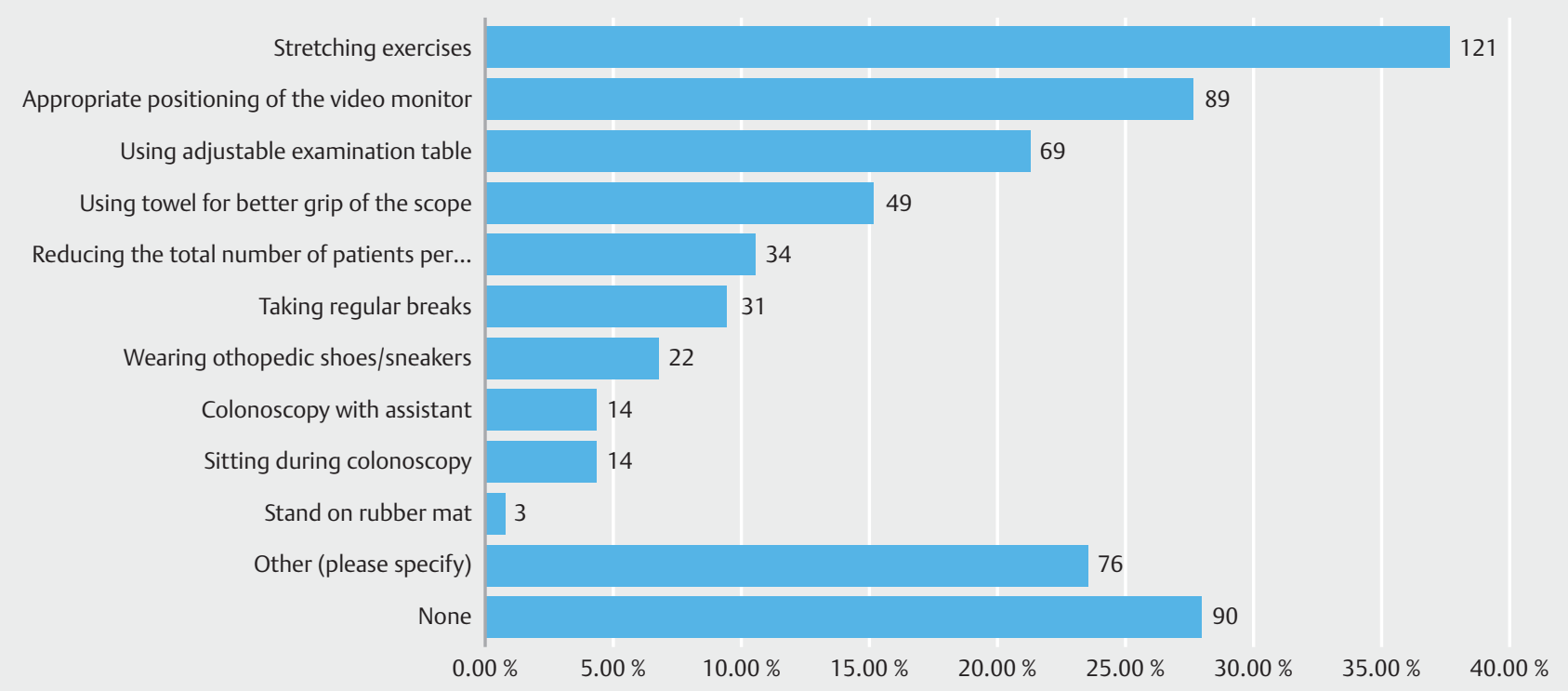

* 90 respondents did not report any modifications to practice, some reported multiple. 33 skipped the question.

Fig. 2 Modification made by colonoscopists $(n=163)^{*}$.

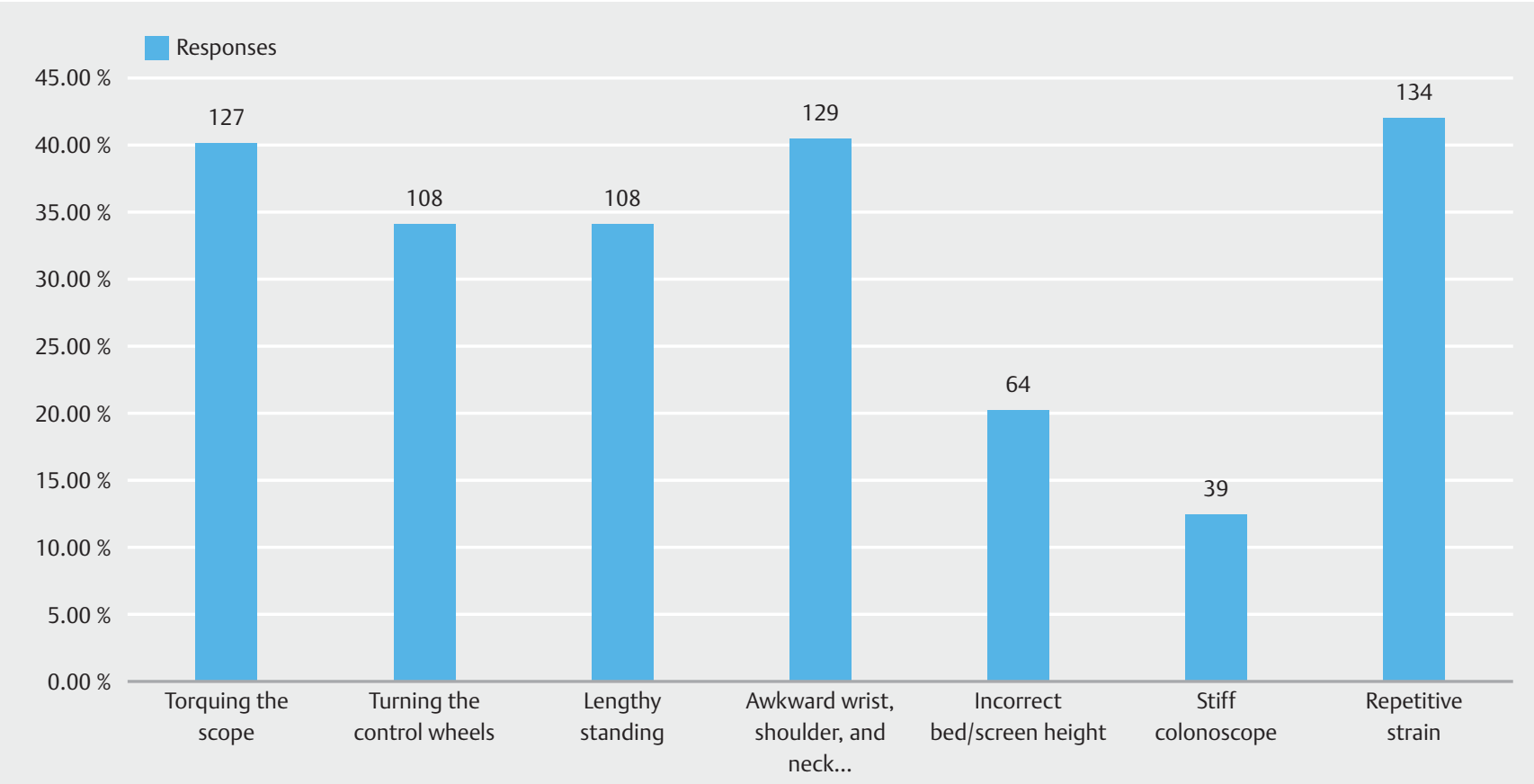

*Answered: 302, Skipped: 17. Multiple mechanisms reported by some colonoscopists

Fig. 3 Presumed causative mechanisms of CRI*.

There are some limitations to this study. First, this is a selfreported survey-based study. This may have increased the likelihood that severely affected endoscopists would respond. Also, the majority of respondents practice in the UK. It is also important to consider that some endoscopists might do other endoscopic (like ERCP and EUS) or non-endoscopic physically demanding tasks that can affect the same anatomical region; however, evaluating that was beyond the scope of this study. 


\section{Conclusion}

A significant proportion of colonoscopists experience CRI. The majority of the suggested modifications to practice can be adopted by any endoscopist. Our results highlight the need to recognize CRI as an important occupational health hazard and to adopt preventative strategies routinely in the future.

\section{Competing interests}

The authors declare that they have no conflict of interest.

\section{References}

[1] Ofori E, Ramai D, John F et al. Occupation-associated health hazards for the gastroenterologist/endoscopist. Ann Gastroenterol 2018; 31 : 448-455

[2] Levy I, Gralnek IM. Complications of diagnostic colonoscopy,upper endoscopy, and enteroscopy. Best Pract Res Clin Gastroenterol 2016; 30: 705-718

[3] Bénard F, Barkun AN, Martel M et al. Systematic review of colorectal cancer screening guidelines for average-risk adults: Summarizing the current global recommendations. World J Gastroenterol 2018; 1 ; $124-138$

[4] Shergill AK, Asundi KR, Barr A et al. Pinch force and forearm muscle load during colonoscopy: a pilot study. Gastrointest Endosc 2009; 69: 142-146

[5] Harvin G. Review of musculoskeletal injuries and prevention in the endoscopy practitioner. J Clin Gastroenterol 2014; 48: 590-594

[6] Ridtitid W, Cote GA, Leung W et al. Prevalence and risk factors for musculoskeletal injuries related to endoscopy. Gastrointest Endosc 2015; 81: 294-302.e4

[7] Yung DE, Banfi T, Ciuti G et al. Musculoskeletal injuries in gastrointestinal endoscopists: a systematic review. Expert Rev Gastroenterol Hepatol 2017; 11: 939-947

[8] Mohankumar D, Garner H, Ruff K et al. Characterization of right wrist posture during simulated colonoscopy: an application of kinematic analysis to the study of endoscopic maneuvers. Gastrointest Endosc 2014; 79: 480-489
[9] Villa E, Attar B, Trick W et al. Endoscopy-related musculoskeletal injuries in gastroenterology fellows. Endosc Int Open 2019; 07: E808E812

[10] Austin K, Schoenberger H, Sesto M. Musculoskeletal injuries are commonly reported among gastroenterology trainees: results of a national survey. Dig Dis Sci 2019; 64: 1439-1447

[11] Kuwabara T, Urabe Y, Hiyama T et al. Prevalence and impact of musculoskeletal pain in Japanese gastrointestinal endoscopists: a controlled study. World J Gastroenterol 2011; 17: 1488-1493

[12] Morais R, Vilas-Boas F, Pereira P et al. Prevalence, risk factors and global impact of musculoskeletal injuries among endoscopists: a nationwide European study. Endosc Int Open 2020; 8: E470-E480

[13] Geraghty J, George R, Babbs C. A questionnaire study assessing overuse injuries in United Kingdom endoscopists and any effect from the introduction of the National Bowel Cancer Screening Program on these injuries. Gastrointest Endosc 2011; 73: 1069-1070

[14] Buschbacher R. Overuse syndromes among endoscopists. Endoscopy 1994; 26: 539-544

[15] Shergill AK, McQuaid KR. Ergonomic endoscopy: An oxymoron or realistic goal? Gastrointest Endosc 2019; 90: 966-970

[16] Cohen DL, Naik JR, Tamariz LJ et al. The perception of gastroenterology fellows towards the relationship between hand size and endoscopic training. Dig Dis Sci 2008; 53: 1902-1909

[17] Cappell MS. Colonoscopist's thumb: DeQuervains's syndrome (tenosynovitis of the left thumb) associated with overuse during endoscopy. Gastrointest Endosc 2006; 64: 841-843

[18] Pedrosa MC, Farraye FA. ASGE Technology Committee. et al. Minimizing occupational hazards in endoscopy: personal protective equipment, radiation safety, and ergonomics. Gastrointest Endosc 2010; 72: 227-235

[19] Shergill AK, McQuaid KR, Rempel D. Ergonomics and GI endoscopy. Gastrointest Endosc 2009; 70: 145-153

[20] Maciel DP, Millen RA, Xavier CA et al. Musculoskeletal disorder related to the work of doctors who perform medical invasive evaluation. Work 2012; 41: 1860-1863

[21] Khan R, Scaffidi MA, Satchwell J et al. Impact of a simulation-based ergonomic training curriculum on work-related musculoskeletal injury risk in colonoscopy. Gastrointest Endosc 2020; 92: 1070-1080

[22] Murphy J, Halloran S, Gray A. Cost-effectiveness of the faecal immunochemical test at a range of positivity thresholds compared with the guaiac faecal occult blood test in the NHS Bowel Cancer Screening Programme in England. BMJ Open 2017; 7: e017186 